\title{
Addressing the gap between school and university in South Africa: exposing grade 11 learners to the integrated and applied nature of science and commerce using Geoscience examples
}

\author{
G.R Drennan ${ }^{1}$, S. Benvenuti ${ }^{2}$, M. Evans ${ }^{3}$ \\ 1- School of Geosciences, University of the Witwatersrand, Private Bag 3, Wits 2050, Johannesburg, South Africa. Emalls: gillian.drennan@wits.ac.za \\ 2- School of Economic \& Business Sciences, University of the Witwatersrand, Private Bag 3, Wits 2050, Johannesburg, South Africa. Emalls: susan.benvenuti@ \\ WITS.AC.ZA \\ 3- School of Geography, Archaeology and Environmental Sciences, University of the Witwatersrand, Private Bag 3, Wits 2050, Johannesburg, South Africa. \\ EMAlLS: MARY.EVANS@WITS.AC.ZA
}

Abstract: Geoscience Education is not included in the School curriculum in South Africa as a stand-alone subject area. Some concepts are embedded in other subject areas such as Plate Tectonic Theory in Geography and Evolution in Life Sciences. Consequently, most students who do register for a BSc degree at South African Universities do not initially intend to study Geology. Minimum entry requirements for different disciplines in the Faculty of Science at the University of the Witwatersrand (Wits) mean that most of the Geology I registrations are by students not qualifying for Mathematical or Physical Sciences. Biological Sciences can only accommodate a portion of these students so the remainder of the students end up in Geology because they wish to obtain a degree and are "forced to do Geology". In an attempt to introduce future students to a broader view of Science, and in particular to Geoscience, Wits has started offering certified Short Courses at NQF Level 4 (National Qualification Framework school leaving certificate level). In 2016 Wits ran the Wits Integrated Experience in Science and in 2017, the Wits Integrated Experience in Science and Commerce, short courses. Learners were exposed to the integrated nature of various Science disciplines and the integrated nature of Science and Commerce through enquiry based, problem solving learning opportunities. The target audience was Grade 11 learners as they have not yet applied to any university and have yet to make subject choices and degree choices. By participating in the short course they are exposed to a variety of disciplines and through investigating real problems, they are exposed to the interdisciplinary nature of these disciplines. In 2016 the learners solved a murder mystery and in 2017, they had to scenario plan for an impending meteorite impact just south of Johannesburg. This scenario planning helped learners to see the relationship between Science disciplines and between Science and Commerce. This is important as the initiative is designed to assist learners in actively choosing their Science and/or Commerce majors and to encourage learners to consider taking innovative major combinations that might cross traditional Faculty boundaries.

\begin{abstract}
Manuscript:
Received: Quadrennial Conference of the International Geoscience Education Organization Accepted: 05/06/2018

Citation:Drennan G.R., Benvenuti S., Evans M. 2018. Addressing the gap between school and university in South Africa: exposing grade 11 learners to the integrated and applied nature of science and commerce using Geoscience examples. Terræ Didatica, 14(3):339-344. URL: http://www.ige.unicamp. br/terraedidatica/.
\end{abstract}

Keywords: Geology, short course, grade 11 learners, student recruitement

Thematic line: Geosciences in Higher Education.

\section{Introduction}

In the Wits Vision 2022 Strategic Framework the University of the Witwatersrand has committed itself to "providing a distinct, intellectually stimulating, challenging and rewarding research and educational experience to all its students, staff, alumni, partners, and guests and all organisations that are associated with the University." Furthermore; the strategy envisions this strategy will position the University as a gateway to research and intellectual engagement in Africa, and a preferred destination for talented students. The objectives under this strategic priority include: (1) Attract highly talented students from around the world and provide a unique student-centred and research-driven experience without compromising Wits' commitment to local imperatives; (2) Re-invigorate Wits' reputation for supporting the participation of students and scholars from all diverse backgrounds who have the potential to benefit from the University's educational opportunities and arrangements, (3) Attract, develop and retain high caliber and distinguished scholars and support staff by offering a welcoming and supportive environment noted for diversity and high level intellectual achievement, (4) Cultivating a positive and lasting distinct experience for all who become associated with Wits, by promoting 
critical enquiry, debate, independence, accountability, and the public good.

According to Freedman (2013) an estimated $20 \%$ to $50 \%$ of students enter higher education as "undecided" and an estimated $75 \%$ of students change their field of study at least once before graduation. Furthermore, it is also important to note that "decided" students are not necessarily basing their decision of the field of study based on factual research and self-reflection. In a study by Beggs et al. (2008), when students were asked to elaborate on their career decision-making process, factors that played a role included a general interest the student had in the subject he or she chose; family and peer influence; and assumptions about introductory courses, potential job opportunities, and characteristics of the major subject/s. While these may be valid factors, to some extent, the study ultimately implied that students are choosing their field of study based on influence and assumption rather than through an understanding of their own personal goals and values. The choice of the field of study can have a significant positive or negative effect on the student experience, affecting retention, engagement, student learning, academic standing, setting of academic and career goals, and more.

The high drop-out rates and failure rates in the first year of study in the Faculty of Science at Wits University (between 50\% in 2012 and 47\% in 2016) indicates that many students have a very uncertain start at university, generally through a combination of factors. These factors include lack of accurate initial information, poor course choices, failure to get into their first choice of degree programme, and unrealistic expectation of the amount of work and time involved in university study.

\section{Wits Faculty challenges}

The Faculty of Science has observed a decline in student registrations at first year level from feeder schools that are known to offer excellent backgrounds in mathematics and in physical sciences - prerequisites for accessing degree programmes in the Faculty of Science. The Faculty of Science therefore, identified a need to broaden exposure to Wits as a 'university of choice' for tertiary education. In addition, the student profile has changed with fewer students selecting science as a first choice, and those that do select science very often have little or no knowledge of the possible direction that they may want to proceed with in science. Consequently, they select courses based on erroneous decision making or unrealistic expectations of what such choices might prepare them for, often resulting in deregistration during the year, poor performance in some courses and possible failure and exclusion at the end of their first year.

It was believed that the Wits Integrated Experience in Science (WIES) short course could expose students to the various possible degree courses and supporting facilities that are available in the Faculty of Science at Wits and that by participating in the hands-on, problem solving learning opportunities included in the short course, that learners might change their opinion about choosing to study Science, and Geoscience in particular, at Wits. It was important to target Grade 11 learners, as they would not yet have made their applications to any tertiary institutions. The purpose of this WIES short course was therefore designed to expose learners to skills, knowledge and attitudes in an Integrated Science short course that would assist participants in making informed decisions about subject choices at tertiary level, potential career choices, higher education opportunities and the world of work; and to expose learners to a variety of study methods and skills pertaining to assessment processes.

This WIES short course is unique and thus cannot be compared to anything currently on offer at any other South African Tertiary institution as no other Tertiary institutions are offering such certified short courses and there is a demand for such courses (learners are expected to obtain at least 4 NQF Level 4 Certificates as part of their Life Orientation Portfolio to meet the requirements of Life Orientation which is a compulsory school subject). The strength of offering such a course is that local Life Orientation teachers are looking for short courses to promote to their learners and the Faculty of Science would like to use the short course as a way of marketing itself as a preferred destination for tertiary studies to students from invited feeder schools. All participants had to attend all contact sessions and complete the required project in order to qualify for the Certificate of Competence.

\section{The Wits Integrated Experience in Science (WIES 2016)}

The WIES 2016 short course responds directly to the objectives presented in the Wits Vision 2022 Strategic Framework which are: (a) to attract highly talented students and provide a unique studentcentred and research-driven experience without 
compromising Wits' commitment to local imperatives, and (b) to cultivate a positive and lasting distinct experience for all who become associated with Wits, by promoting critical enquiry, debate, independence, accountability, and the public good.

On Friday, $16^{\text {th }}$ September 2016, the Faculty of Science hosted 99 top Grade 11 achievers from 14 different feeder schools. The learners spent the full day with the Faculty of Science being exposed to different aspects of science, while at the same time, being exposed to the university campus and finding out how varied and interesting science can be. Feeder schools were invited to choose their own team of 5 pupils who were top of the class in science/mathematics/geography and/or biology. The teams were to compete in gathering information obtained through evidence-based learning in the disciplines of Archaeology, Geography, Geology, Molecular and Cell Biology, Chemistry, Computational and Applied Mathematics, Actuarial Sciences and Astrophysics to solve a 'murder mystery'.

After an exciting day, learners returned to their schools and worked with the information they collected. In order to solve the mystery of "who dunnit?" they had to integrate all their data/findings and put together a group presentation that they would deliver to their peers and a panel of judges one month later. Each learner who successfully participated in the group project and who successfully integrated the data in solving the mystery received a Wits Certificate of Competence in Science. There were also prizes to be won.

The WIES 2016 scenario was as follows: the body of a Post-Doctoral candidate was found by a gardener, buried in a shallow grave in a newly dug flower bed on campus. The police called in 'forensic scientists' from the Faculty of Science, to investigate the murder.

- Archaeology provided information about the burial site, the profile of the victim and the profile of possible perpetrators based on evidence found in the grave.

- From Geography they learned about the pollens and spores that were found on the victims clothing, indicating he had recently visited a wetland.

- In Geology learners used a hand-held XRF gun to analyse the geochemistry of soils around the body, establishing that the layer immediately above the body was enriched with calcium and carried out tests of the liquid found in a water bottle in the grave. This was particularly acidic when compared to standard tap water and sea water, which were used as controls.

- In Molecular and Cell Biology learners established from DNA that tissue samples found on the victim belonged to a female. This DNA was therefore compared to that of the victim's ex-girlfriend as well as his laboratory partner, two females known to be associated with the victim.

- The blood chemistry of the victim was analysed by the Chemists, and found to contain very high levels of Aspirin.

- In Computational and Applied Mathematics, learners used computer technology to carry out picture enhancements of photographs taken of notes and shopping lists found in the homes of the ex-girlfriend and the laboratory partner, both of which had Aspirin as an item to purchase but only one of them also had agricultural lime as a shopping item.

- Actuarial Sciences used large data sets to highlight how males are more likely to die young than females

- An online app was used by the Physicists to investigate the phase of the moon, highlighting how dark the grave site was at the suspected time of the murder.

On the 14th October 2016, learners assembled to present their group findings and to be evaluated. Teachers and parents were invited to the presentations and the award ceremony. All participants were awarded their certificates, which qualify for inclusion in their Life Orientation (LO) portfolio and count towards their final LO grades.

\section{Wits Integrated Experience in Science and Commerce (WIES\&C 2017)}

In 2017 the Faculty of Science, joined by the Faculty of Commerce, Law and Management (CLM), ran the Wits Integrated Experience in Science and Commerce 2017 (WIES\&C) short course. The course was designed to be fun, experiential and interactive and involved an integrated problem solving exercise that would assist participants in making informed decisions about subject choices, careers, and higher education opportunities, leading to the world of work in both Science and Commerce.

\begin{tabular}{c|c|c|c|c|c}
\hline (C) Terrae Didat. & Campinas, SP & v.14 & n.3 & p. 339-344 & jul./set. 2018 \\
\hline
\end{tabular}


The revised short course was offered to selected feeder schools that not only exposed learners to skills and knowledge associated with Science, but combined with Commerce to expose learners to the need for interdisciplinary approaches to realworld problem solving. Schools that were invited were considered to represent those likely to provide students with a strong possibility of succeeding at either Science or Commerce as both Faculties have similar minimum entry requirements.

The interactive short course took place on Friday, 28 July 2017. During this day, students were exposed to specialist academics in Science and CLM and were able to gather information related to an "impending meteorite impact" - the learners were told that they were to serve as partners with these academics in processing data collected and in proposing how to deal with such a crisis from a scientific, economic and management perspective. Each team rotated through 3 Science and 3 Commerce activities and each team had to complete all 6 activities over the course of the day. Each team was accompanied by Wits Students during the day. Activities were carried out on two of the Wits Campuses, exposing students to state-of-the-art lecture and laboratory venues as well as to the general environs of the university.

Science activities included:

- Physics and Geosciences - Finding meteorites and a computer game, "Where will it be safe?" developed in the School of Geosciences

- Chemistry and Molecular and Cell Biology - Effects of visitors from space on isotope balances

- Mathematical Sciences - Computer game modelling effects of meteorite impact

CLM activities included:

- Information Systems - Using (Big) Data, Crowd Sourcing and Information for disaster response decision making and planning.

- Economics and Finance - Managing financial fallouts: food security and the futures market - what might the costs of impact be?

- Insurance and Risk and Management - Planning for and managing risks - the evacuation game

Following this day of information/data gathering teams were required to present their scenario planning to review panels on Friday 15th Septem- ber, 2017, and were judged on their report-back presentations. This report-back day culminated in a graduation ceremony where certificates and prizes were once again handed out.

\section{Course content summary}

The course provided an introduction to basic laws, principles and units of measurement within the disciplines of Science including Chemistry, Physics, Archaeology, Geography, Geology, Applied Mathematics, Statistics and Computer Science as well as an introduction to basic laws, principles and procedures within the disciplines of Commerce, Law and Management, including Economics, Finance, Law, Management and Information Systems. Learners engaged with emerging technologies, large data sets, statistical models, computer applications, geochemical and geophysical analyses, as well as with emerging trends and practices in business, information systems, law, economics, data management and disaster management.

At the end of the course, it was anticipated that participants would be able to identify and solve a problem using scientific thought, methods and techniques in which responses display critical and creative thinking, collect, organise and critically evaluate information, demonstrate an understanding of the world as a set of related systems by recognising that problem solving contexts do not exist in isolation, work effectively with others as a member of a team or group, communicate effectively using visual, mathematical and or language skills to present their findings reliably and accurately in writing and verbally, and challenge preconceived notions of the identity of a scientist/economist with respect to gender, race, age, etc.

\section{Evaluation of the effectiveness of the short course}

The study adopted a two-way interlinked survey process: a pre- and a post-WIES and WIES\&C survey was developed and Ethical Clearance was sought from the Wits Human Research Ethics Committee (HREC; H16/07/42). The study adopted a quantitative questionnaire-based methodology using a paper based survey. A survey tool offered a suitable approach for obtaining student feedback on perceptions, and allowed for maximum participation with limited space for open-ended input. The tools were administered during the two 
engagements with the learners at the very start of the WIES and WIES\&C data gathering days at Wits, and at the end of the presentation and prize giving events. An information participation sheet, as per ethics requirements, was attached to the survey. After the data was collected via the 2 questionnaires a Microsoft Excel package was used to analyse the data. The qualitative responses were analysed separately using a thematic analysis approach, with the purpose of identifying key themes emerging from the narratives.

The details of these analyses are the subject of a dedicated paper. Of interest, however, is that the majority of grade 11 learners have a very limited perception of what science and commerce are, and no participants considered geology, geography or earth sciences as scientific disciplines in the preshort course surveys. A variety of responses were recorded for the question relating to what the first word was that came to mind when thinking about a scientist, however, the most common words or descriptors recorded include: smart (8), intelligence/intellectual/intelligent (14), innovation/ innovative/innovator (8), and chemicals (8). Quite clearly this highlights the limited understanding by learners of what it means to be a scientist. More grade 11 learners recognized that geology and geography did play role in solving real-world problems after they had been a part of the WIES and WIES\&C initiative. One student wrote "Scientists study the scientific aspects of things in order to try and further the development of our society, while trying to keep the environment sustainable".

From the demographic information, collected in the pre-intervention surveys, it was seen that some $63 \%$ of participants were male and $36 \%$ were female. This is in stark contrast to the statistics for first year students registering for the General Academic First Bachelor's Degree in Science where $53 \%$ of new students are male and $47 \%$ are female (Wits Facts and Figures 2015-2016). Geology classes at Wits generally have $50 \%$ females in the class. Of the participants an average of $51 \%$ represented so-called previously disadvantages individuals (Black, Coloured and Indian), 39\% indicated that they were white (so-called advantaged individuals) and $6 \%$ indicated that they represented another population grouping. Faculty statistics show that of the first-time first-year students registering for a BSc degree, $89 \%$ are in fact from previously disadvantaged backgrounds and only $11 \%$ of new students are white (advantaged). In Geology, the percentage of white students in first year is lower at between $4 \%$ and $5 \%$. This is an important finding as it indicates that without initiatives such as WIES and WIES\&C, and the exposure that such initiatives provide to potential students, our institution was not regarded as the 'University of Choice'. This perception changed, however, in the postintervention survey where more than $80 \%$ of grade 11 learners indicated that they would consider Wits as the tertiary institution where they would consider registering. Of the randomly selected eight WIES 2016 participants that were checked, 6 had registered at Wits, which is encouraging. Additional research will follow as the WIES\&C short course continues.

Analysis of the post-intervention surveys show that the majority of learners were highly satisfied with WIES and WIES\&C short courses. Most learners who participated reported a very positive impact of the programme on the development of their skills.

- $100 \%$ of participants were satisfied with the overall learning experience during the short courses.

- $95-96 \%$ of the participants were satisfied with how the course developed their ability to think critically.

- $90-92 \%$ of participants were satisfied with how the course helped develop their practical skills.

- $92-94 \%$ of participants were confident that the course helped them to develop their analytical ability.

- $80-83 \%$ of participants were satisfied with how the course developed their communication skills.

- $86-88 \%$ of participants were satisfied with how the course developed their interpersonal skills.

- $90-94 \%$ of participants were satisfied with the manner in which the courses developed their problem-solving skills.

- $63-66 \%$ of participants were of the view that the courses prepared them for their career choice.

- $92-95 \%$ of participants were of the view that the courses helped them to develop subject specific knowledge.

- $94-96 \%$ of participants were satisfied with their ability to develop teamwork skills through the courses.

- $96-97 \%$ of participants were satisfied with the development of their working knowledge of science through attending the courses. One student wrote: "The experience as a whole was

\begin{tabular}{c|c|c|c|c|c}
\hline (C) Terrae Didat. & Campinas, SP & v.14 & n.3 & p. 339-344 & jul./set. 2018 \\
\hline
\end{tabular}


very educational \& definitely (sic) helped me in my thinking around science". Many participants indicated that they had never considered geology as a science or as a career and a number expressed their surprise at just how much of daily life is affected by geology. It is hoped that more learners will consider studying geology in the future as a consequence of having participated in the WIES and WIES\&C short courses.

\section{Conclusions}

The Wits Vision 2022 Strategic Framework articulates a vision that elevates Wits' position as one of the internationally leading researchintensive universities and a gateway to knowledge and understanding in Africa. It provides the overarching framework for more detailed plans based on current imperatives, and will shape strategic thinking during the respective planning cycles. In response to strategic imperatives and informed by the Wits Vision 2022 Strategic Framework as well as the Learning and Teaching Policy (2015 2019), the Faculty of Science and the Faculty of Commerce, Law and Management have initiated faculty-wide and inter-faculty active participation of grade 11 learners through the "Wits Integrated Experience in Science" (2016) and the "Wits Integrated Experience in Science and Commerce" (2017 onwards). These initiatives were aimed at building better lasting relationships with feeder schools and attracting some of the highly talented learners that the basic education system can produce. The feedback from all participants, teachers and parents has given impetus to increasing this initiative to reach more schools going forward. The success of the initiative has resulted in other Deans encouraging their staff to introduce similar initiatives in their faculties. The potential exists to create multi-disciplinary short courses that could be run by all faculties, thereby increasing the number of grade 11 learners developing a meaningful relationship with Wits.

Exposing the potential students to the campus, the academics and the "Wits Experience" in general, has already reflected positively in attracting students to Wits. By exposing potential students to the significance and importance of geology on every-day life will it is hoped that students will register for degrees involving geology as a first choice, rather that attracting students who simply cannot register for any other degree programme.
The WIES\&C 2018 is already under way and grade 11 learners will be required to scenario plan to avoid future water crises using the data and skills that they will be exposed to in 2018. Planning for WIES\&C 2019 has begun, and hopefully exciting geological aspects included in these initiatives will continue to promote geology as a future subject and career choice.

\section{Acknowledgements}

The authors wish to acknowledge financial support received from Wits Marketing and Communications, the Faculty of Science and the Faculty of Commerce, Law and Management. We also greatly appreciate the sponsorship of Laptop prizes from IBM South Africa, T-shirts and "goodies" from the DST-NRF Centre of Excellence in Mathematics and Statistical Sciences (MaSS) and book prizes donated by the School of Geosciences. The WIES and WIES\&C initiatives would not be possible without the continued participation of the dedicated academic and support staff as well as students who assist each year. Without the support and participation of learners and teachers from the local feeder schools this initiative would not have been possible.

\section{References}

Beggs J., Bantham J., Taylor S. 2008. Distinguishing the factors influencing college students' choice of major. College Student Journal, 42(2):381-394.

Freedman L. 2013. The Developmental Disconnect in Choosing a Major: Why Institutions Should Prohibit Choice until Second Year. Butler University. The Mentor an Academic Advising Journal. URL: https:// dus.psu.edu/mentor/2013/06/disconnect-choosingmajor/, accessed 1/10/2016.

Goree C.T., Marszalek J.F. 1995. Electronic surveys: Ethical issues for researchers. College Student Affairs Journal, 15(1):75-79.

University of the Witwatersrand. Wits Vision 2020: Strategic Framework. http://www.wits.ac.za/AboutWits/ StrategicPlanningDivision, University of the Witwatersrand, Johannesburg, South Africa, pg 3 - 37, accessed 14/01/18.

Strategic Planning Division, First Year Student Experience Survey 2011; 2012; 2013 Strategic Planning Division, Wits Facts and Figures 2015 - 2016, https:// www.wits.ac.za/media/wits-university/footer/aboutwits/facts-and-figures/documents/Wits-Fact--Figures2017-2018.pdf, accessed 22/01/18. 